\title{
Gene Transfer into the Airway Epithelium of Animals by Targeting the Polymeric Immunoglobulin Receptor
}

\author{
Thomas Ferkol, ${ }^{\S}$ Jose C. Perales, ${ }^{\star}$ Elizabeth Eckman, ${ }^{\S}$ Charlotte S. Kaetzel, ${ }^{\ddagger}$ Richard W. Hanson, ${ }^{\star}$ and Pamela B. Davis $\$$ \\ ${ }^{\S}$ Department of Pediatrics, Rainbow Babies and Childrens Hospital; ${ }^{\ddagger}$ Departments of Pathology and *Biochemistry, Case Western \\ Reserve University School of Medicine, Cleveland, Ohio 44106
}

\begin{abstract}
Genes of interest can be targeted specifically to respiratory epithelial cells in intact animals with high efficiency by exploiting the receptor-mediated endocytosis of the polymeric immunoglobulin receptor. A DNA carrier, consisting of the Fab portion of polyclonal antibodies raised against rat secretory component covalently linked to poly-L-lysine, was used to introduce plasmids containing different reporter genes into airway epithelial cells in vivo. We observed significant levels of luciferase enzyme activity in protein extracts from the liver and lung, achieving maximum values of $13,795 \pm 4,431$ and $346,954 \pm 199,120$ integrated light units (ILU) per milligram of protein extract, respectively. No luciferase activity was detected in spleen or heart, which do not express the receptor. Transfections using complexes

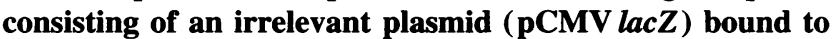
the bona fide carrier or the expression plasmid (pGEMluc) bound to a carrier based on an irrelevant Fab fragment resulted in background levels of luciferase activity in all tissues examined. Thus, only tissues that contain cells bearing the polymeric immunoglobulin receptor are transfected, and transfection cannot be attributed to the nonspecific uptake of an irrelevant carrier-DNA complex. Specific mRNA from the luciferase gene was also detected in the lungs of transfected animals. To determine which cells in the lung are transfected by this method, DNA complexes were prepared containing expression plasmids with genes encoding the bacterial $\beta$-galactosidase or the human interleukin 2 receptor. Expression of these genes was localized to the surface epithelium of the airways and the submucosal glands, and not the bronchioles and alveoli. Receptor-mediated endocytosis can be used to introduce functional genes into the respiratory epithelium of rats, and may be a useful technique for gene therapy targeting the lung. (J. Clin. Invest. 1995. 95:493502.) Key words: polymeric immunoglobulin receptor $\bullet$ secretory component $\bullet$ trachea $\bullet$ epithelial cells $\bullet$ gene transfer
\end{abstract}

Address correspondence to Thomas Ferkol, M.D., Pediatric Pulmonology, Rainbow Babies and Childrens Hospital, Case Western Reserve University, 11100 Euclid Avenue, Cleveland, Ohio 44106-6006. Phone: 216-844-3267; FAX: 216-844-5916. C. S. Kaetzel's present address is Department of Pathology and Laboratory Medicine, University of Kentucky College of Medicine, Lexington, KY 40536.

Received for publication 13 May 1994 and in revised form 21 September 1994.

J. Clin. Invest.

(C) The American Society for Clinical Investigation, Inc.

0021-9738/95/02/0493/10 \$2.00

Volume 95, February 1995, 493-502

\section{Introduction}

The respiratory epithelium is the primary target tissue for gene therapy of cystic fibrosis, and several methods of gene transfer permit the introduction of functional genes into cells of the respiratory tract in animals. Receptor-mediated gene transfer has particular appeal for it may provide a noninfectious method for delivering DNA to specific target cells. This method exploits the process of receptor-mediated endocytosis to introduce DNA exclusively into cells that bear the target receptor. The plasmid DNA transferred in this manner can be of considerable size (1), thus permitting flexibility not only in the selection of the transgene but also in the choice of promoter and enhancer elements. The delivery of exogenous DNA using receptor-mediated systems depends on the stability of the carrier-DNA complex, the presence and number of receptors on the surface of the targeted cell, the receptor-ligand affinity and interaction, and efficient internalization of the complex $(2,3)$. Furthermore, the transferred genes must escape from endosomes $(4,5)$ and traffic to the target cell's nucleus. This strategy has been used to introduce reporter genes into cells in culture, and results in transient but high levels of expression from the transgene. However, receptor-mediated gene transfer systems have produced variable results in vivo. The transgene is expressed for a short time at low levels $(6,7)$ unless invasive manipulation of the animal, such as partial hepatectomy, is performed (810). However, Perales and colleagues (11) have recently shown that surgical manipulation of the liver was not necessary for prolonged expression of transgenes introducted into hepatocytes via the asialoglycoprotein receptor. For airway epithelial cells, adenovirus-polylysine and transferrin-adenovirus-polylysine vectors achieved high efficiency transfection of cells in culture $(1,5)$. However, when the same conjugates were used to introduce exogenous genes into cotton rats via the intratracheal route, the transgene was transiently expressed at low levels (12).

We have demonstrated that in primary cultures of human tracheal epithelial cells, targeting the polymeric immunoglobulin receptor $(\mathrm{pIgR})^{1}$ can be used for the specific delivery of reporter genes to cells that bear the receptor (2). This receptor undergoes efficient internalization and is specifically adapted for the nondegradative transfer of large molecules. In addition, the cellular distribution of pIgR expression in the surface epithelium and serous cells of the submucosal glands conforms to that of the cystic fibrosis transmembrane conductance regulator in human airways $(13,14)$. In this report, we show that tar-

1. Abbreviations used in this paper: IL2r, human interleukin 2 receptor; pIgR, polymeric immunoglobulin receptor; SC, secretory component; SPDP, $N$-Succinimidyl 3-(2-pyridyldithio) proprionate; X-gal, 5 Bromo-4-chloro-3-indolyl- $\beta$-galactopyranoside. 
geting the pIgR in rats results in significant expression of the transgene in tissues that contain receptor-bearing cells, which was maximal $6 \mathrm{~d}$ after transfection.

\section{Methods}

Materials. DNA-modifying enzymes, nucleotides, and 5-Bromo-4chloro-3-indolyl- $\beta$-D-galactopyranoside were purchased from Boehringer Mannheim (Indianapolis, IN). GeneScreen Plus and [ $\left.\alpha^{32} \mathrm{P}\right] \mathrm{dCTP}$ were obtained from DuPont-New England Nuclear (Boston, MA). Protein A MAPS agarose columns were purchased from Bio Rad (Richmond, CA). Papain and poly-L-lysine were obtained from Sigma Chemical Co. (St. Louis, MO), and N-Succinimidyl-3-(2-pyridyldithio)proprionate was purchased from Pierce Chemical Co. (Rockford, IL). Promega (Madison, WI) assay reagents were used to measure luciferase activity. Reverse transcriptase and polymerase chain reaction reagents were obtained from Perkin Elmer Cetus (Norwalk, CT). The mouse monoclonal anti-interleukin 2 receptor antibody was obtained from Dako Corp. (Carpenteria, CA).

Production of carrier-DNA complexes that target the polymeric immunoglobulin receptor. Two features of this system are critical for the successful introduction of genes into the airway epithelial cells: $(a)$ anti-secretory component (SC) Fab antibodies serve as the targeting ligand in this gene transfer system, which permits specific delivery of genes to cells that express PIgR; and $(b)$ the condensation of the DNA by the anti-SC Fab-based carrier into highly compact complexes suitable for efficient uptake via an endocytic pathway.

Preparation of Fab antibody fragments. Polyclonal antisera were raised in rabbits against SC purified from rat bile (15). The antibody recognizes purified $\mathrm{SC}$, secretory $\mathrm{IgA}$, and the $\mathrm{pIgR}$, but not dimeric $\operatorname{IgA}$. The antiserum was stored in $1-\mathrm{ml}$ aliquots at $-20^{\circ} \mathrm{C}$ until the immunoglobulin $\mathrm{G}(\mathrm{IgG})$ was isolated. The antibody was isolated by Protein A MAPS agarose chromatography as described by the manufacturer. Fab fragments were prepared and isolated as described previously for the anti-human SC Fab-based carrier (2). Briefly, $2 \mathrm{mg}$ of isolated IgG was treated with $20 \mu \mathrm{g}$ of insoluble papain attached to agarose beads for $12 \mathrm{~h}$ at $37^{\circ} \mathrm{C}$ in the presence of $100 \mathrm{mM}$ sodium acetate ( $\mathrm{pH}$ 5.5) $50 \mathrm{mM}$ cysteine, and $1 \mathrm{mM}$ EDTA. The Fab fragment was separated from intact antibody and $\mathrm{Fc}$ fragments by Protein A chromatography. An irrelevant Fab was generated by papain digestion of IgG from preimmune rabbit serum. Cleavage of the IgG was verified by separating the digestion products using SDS-PAGE. The Fab product migrated as a band at $52 \mathrm{kD}$.

Preparation of the anti-SC Fab-polylysine carrier. The Fab fragment of the anti-SC antibody was covalently linked to poly-L-lysine (average $M_{\mathrm{r}}=20 \mathrm{kD}$ ) using the heterobifunctional cross-linking reagent $N$-Succinimidyl 3-(2-pyridyldithio) proprionate (SPDP) (16); $2.5 \mu 1$ of $20 \mathrm{mM}$ SPDP in absolute ethanol was incubated with the anti-SC Fab fragment $(200 \mu \mathrm{g})$ in $0.1 \mathrm{M}$ phosphate buffered saline (PBS), pH 7.5 , at $22^{\circ} \mathrm{C}$ for $60 \mathrm{~min}$. After introduction of 2-pyridyl disulfide structures onto the Fab fragment, unreacted SPDP and low molecular weight reaction products were removed by dialysis. The disulfide bridges of the modified Fab fragment were cleaved with $25 \mathrm{mM}$ DTT, pH 4.5. 15fold molar excess of poly-L-lysine and SPDP relative to the modified Fab fragment were added, and the reaction was carried out at $22^{\circ} \mathrm{C}$ for $24 \mathrm{~h}$. The conjugate was dialyzed to remove low molecular weight reaction products, and analyzed by separating the resultant proteins using $0.1 \%$ SDS-7.5\% PAGE. These gels showed a broad band that migrated at $>200 \mathrm{kD}$ (data not shown). This slow migration is most likely due to the high proportion of basic amino acids, i.e., lysine, attached to the Fab fragment. A fraction of the Fab fragment did not conjugate to the poly-L-lysine.

Formation of the anti-SC Fab carrier-based DNA complexes. The carrier-DNA complexes were formed using a general technique previously described for a galactosylated polylysine ligand (11), a method different from that used in our previous work targeting the pIgR in vitro (2). The conditions necessary to ensure condensation of the DNA depend on a number of variables, including the size, sequence and physical state of the DNA, the chain length of the poly-L-lysine, and the nature of the ligand. The optimal concentration of sodium chloride required to effectively compact the plasmid is also dependent on these variables (11).

DNA was condensed by the slow addition of the anti-SC Fab carrier in the presence of $400 \mathrm{mM}$ sodium chloride and constant vortexing for $30 \mathrm{~min}$ at room temperature. After the addition of the carrier to the DNA, the sodium chloride concentration in the solution was adjusted by adding 3- $\mu \mathrm{l}$ aliquots of $5 \mathrm{M} \mathrm{NaCl}$. As the ionic strength of the solution was increased, the anti-SC Fab-polylysine-DNA complexes proceeded from an aggregated to a condensed state, and the turbidity of the mixture cleared (11). The final volume of the solutions was 300$500 \mu \mathrm{l}$, and contained $300 \mu \mathrm{g}$ of plasmid DNA in $470-650 \mathrm{mM} \mathrm{NaCl}$. Different final concentrations of sodium chloride in different preparations of the complexes was primarily due to heterogeneity in size of the poly-L-lysine component of the carrier. Based on our previous experiments (11), the optimal charge ratio of the DNA phosphate groups to lysine was approximately $1: 0.7$. The condensation process was monitored by circular dichroism spectroscopy and electron microscopy (11).

The expression plasmid pGL2 (Promega) contained the SV40 viral promoter and enhancer ligated to the Photinus pyralis luciferase gene, and inserted into the Escherichia coli pUC19 vector. The plasmids pCMV lacZ (17) and pCMVIL2r (Saulino, A., and M. L. Drumm, unpublished data), consisting of the cytomegalovirus (CMV) promoter linked to the $E$. coli $\beta$-galactosidase lac $Z$ and the interleukin 2 receptor (IL2r) genes, respectively, were also used as reporter genes. For studies of luciferase activity, these plasmids were used as irrelevant DNA (IDNA) controls. The plasmids were grown in E. coli DH5 $\alpha$, purified on a cesium chloride gradient using standard techniques (18), and treated with RNaseA and $T_{1}$. No contamination with bacterial genomic DNA or RNA was detected by $1.0 \%$ agarose gel electrophoresis of the plasmid preparations. Digestions of the plasmids with restriction endonucleases yielded the appropriate size DNA fragments. The sizes of plasmids are as follows: pGL2, $6.0 \mathrm{~kb}$; pCMV lacZ, $10.9 \mathrm{kB}$; and pCMVIL2r, $5.4 \mathrm{kB}$.

Animals. The anti-rat SC Fab-polylysine carrier was used to transfer reporter genes into the airways and livers of intact animals. Adult, male Sprague-Dawley rats, weighing approximately $250 \mathrm{~g}$, were anesthetized. Using aseptic technique, $0.3-0.5 \mathrm{ml}$ of a solution containing $300 \mu \mathrm{g}$ of an expression plasmid complexed to the carrier was injected slowly ( 1 $\mathrm{min}$ ) into the caudal vena cava. All animals injected with the complexes survived. The rats were killed at different times after infusion of the complexes and various organs were removed for analysis. Mock transfections of animals using DNA complexes consisting of an irrelevant plasmid bound to the carrier or the expression plasmid bound to a carrier made with an irrelevant Fab fragment were also performed in parallel. The animal research protocol was reviewed and approved by the Case Western Reserve University Institutional Animal Care Committee.

Detection of the exogenous plasmid DNA using the polymerase chain reaction. One microgram of genomic DNA isolated from the lungs of transfected and nontransfected rats $6 \mathrm{~d}$ after treatment was amplified as described by the manufacturer. After incubating the solution at $94^{\circ} \mathrm{C}$ for seven minutes to denature the genomic DNA, the DNA was amplified through 25 cycles, using the following primers for the luciferase gene: AGACGAACACTTCTTCATAGTTGACC (luc I), a primer that bind to the $5^{\prime}$ end of the luciferase gene corresponding to positions 1551 to 1576, and TTTCCTCATTAAAGGCATTCCACC (luc II), an antisense primer that corresponds to nucleotide positions 2260 and 2283. The predicted length of the amplified region of DNA was 732 base pairs. $10 \mathrm{ml}$ of amplified DNA was separated by electrophoresis using a $1.6 \%$ agarose gel, transferred to a nitrocellulose filter, and analyzed by Southern blot hybridization with a radiolabeled cDNA probe specific for the luciferase gene.

Detection of luciferase mRNA using the polymerase chain reaction. 
The presence of mRNA transcripts from the luciferase gene in the lungs of rats was determined 6 and $12 \mathrm{~d}$ after transfection by treatment of total cellular RNA with Moloney Murine Leukemia Virus reverse transcriptase and amplification of the resultant cDNA by the polymerase chain reaction. Briefly, $1 \mu \mathrm{g}$ of total rat liver RNA was added to a solution containing $500 \mathrm{nM}$ of $(\mathrm{dT})_{16}$ oligonucleotide primer and 500 $\mathrm{nM}$ of each deoxynucleotide triphosphate, and heated to $42^{\circ} \mathrm{C}$ for $2 \mathrm{~min}$. Reverse transcriptase was added, the mixture was incubated for $30 \mathrm{~min}$ at $42^{\circ} \mathrm{C}$, and $1 \mu \mathrm{l}$ of the cDNA pool was amplified by the polymerase chain reaction, using primers within the chimeric luciferase gene described above. Because of the presence of an intron 66 base pairs in length, the sizes of the amplified sequences from plasmid DNA and cDNA generated from RNA after treatment with reverse transcriptase are different, which distinguished transferred DNA from mRNA transcribed from the transgene. The expected length of the amplified cDNA from the luciferase mRNA was $666 \mathrm{bp}$. As a control, rat glyceraldehyde3-phosphate dehydrogenase (GAPDH) mRNA was also amplified using similar conditions with primer CCATGGAGAAGGCTGGGGC (GAPDH 5'), which corresponds to positions 371 to 389 in the GAPDH gene, and primer CAAAGTTGTCATGGATGACC (GAPDH 3'), an antisense primer which corresponds to positions 546 to 565 . The expected size of the amplified cDNA generated from the rat GAPDH mRNA was 194 base pairs. The RNA isolated from lungs of transfected and nontransfected rats was evaluated. In addition, the same RNA samples not converted to cDNA by reverse transcriptase were used as polymerase chain reaction templates as controls to establish that contaminating plasmid DNA had not been amplified. The products were separated by agarose gel electrophoresis and their identity verified by Southern blot hybridization using a radiolabelled luciferase or glyceraldehyde-3phosphate dehydrogenase DNA probes.

Cytochemical assay for $\beta$-galactosidase activity. Individual cells expressing $\beta$-galactosidase in tissues were identified after incubation with 5-Bromo-4-chloro-3-indolyl- $\beta$-galactopyranoside (X-gal). Briefly, the cells were fixed with a solution of $0.5 \%$ glutaraldehyde in PBS for $10 \mathrm{~min}$, washed twice with PBS, pH 7.5, and then incubated with a solution containing $0.5 \% \mathrm{X}$-gal dissolved in $\mathrm{N}$ - $\mathrm{N}$-dimethylformamide, $5 \mathrm{mM}$ potassium ferricyanate, $5 \mathrm{mM}$ potassium ferrocyanide, and $1 \mathrm{mM}$ magnesium chloride in PBS ( $\mathrm{pH} \mathrm{7.4)} \mathrm{for} 4 \mathrm{~h}$ at $37^{\circ} \mathrm{C}$. After incubation, the tissues were fixed in $2 \%$ para formaldehyde $/ 0.5 \%$ glutaraldehyde in PBS overnight at $4^{\circ} \mathrm{C}$, paraffin embedded, and cut into 5- $\mu \mathrm{m}$ sections. The sections were counter-stained with nuclear fast red, and blue colored cells were identified by light microscopy. In addition, adjacent sections were stained with Alcian blue ( $\mathrm{pH} 2.5$ )/periodic acid Schiff or hematoxylin/eosin using standard protocols (19).

Immunohistochemical staining for the interleukin 2 receptor. The expression of the transgene in tissues transfected with the plasmid pCMVIL2 $r$ was determined by indirect immunofluorescence. Frozen sections $(10 \mu \mathrm{m})$ of trachea were fixed with acetone for $10 \mathrm{~min}$ at $-20^{\circ} \mathrm{C}$ and treated with $0.5 \%$ sodium borohydride in water for $10 \mathrm{~min}$ at $22^{\circ} \mathrm{C}$ to reduce autofluorescence. The sections were then incubated sequentially with a mouse monoclonal anti-interleukin 2 receptor antibody for $1 \mathrm{~h}$ at $37^{\circ} \mathrm{C}$, then fluorescein isothiocyanate-conjugated goat anti-mouse IgG for $1 \mathrm{~h}$ at $37^{\circ} \mathrm{C}$. Both the primary and secondary antibodies were diluted 1:100 in PBS, and between each incubation the slides were washed three times for 5 min with PBS, $\mathrm{pH} 7.5$. The stained tissue sections were examined by fluorescence microscopy using an inverted Zeiss epifluorescence microscope and emitted light was detected by a cooled CCD camera.

Assays for luciferase activity. Tissues were harvested from transfected and control rats after the animals were sacrificed and perfused in situ with cold PBS, pH 7.5, for $5 \mathrm{~min}$. The tissues were homogenized in lysis buffer (Promega) and permitted to incubate at $22^{\circ} \mathrm{C}$ for $10 \mathrm{~min}$. These lysates were centrifuged for $5 \mathrm{~min}$ at $4^{\circ} \mathrm{C}$, and the supernatants were analyzed for luciferase activity. The lysates were assayed for protein content using the Bradford method and the measured integrated light units (10 s interval) were standardized for total protein content
(20). All measurements were performed in triplicate and expressed as an average of the values.

Immunohistochemical staining of rat tracheas for plgR. The expression of pIgR in rat tracheal epithelial cells was determined by indirect immunofluorescence. Tracheal sections were frozen then fixed with acetone at $-20^{\circ} \mathrm{C}$ for $10 \mathrm{~min}$, and incubated sequentially with rabbit antirat $\mathrm{SC}$ for $1 \mathrm{~h}$ at $37^{\circ} \mathrm{C}$, then rhodamine-conjugated goat anti-rabbit IgG for $1 \mathrm{~h}$ at $37^{\circ} \mathrm{C}$. Both antibodies were diluted 1:100 in PBS, pH 7.5. Between each incubation, the slides were washed three times with PBS, pH 7.5. The stained tissues were examined by fluorescence microscopy as described above.

Statistical analysis. Data are expressed as means \pm standard error of the mean (SEM), and evaluated by a nonparametric analysis of variance using the Kruskall-Wallis test (21).

\section{Results}

Construction of the anti-secretory component Fab antibodybased carrier-DNA complexes. An essential step in the assembly of a carrier-DNA complex capable of efficient gene transfer in animals is the condensation of the plasmid DNA to a size and shape suitable for uptake via an endocytic pathway. Perales and colleagues (11) described a procedure for condensation of individual DNA molecules into unimolecular complexes of defined structure by adjusting the charge neutralization of the DNA by the slow addition of ligand-polylysine conjugates in the presence of high concentrations of sodium chloride. This technique permits a change in the conformation of the DNA molecule allowing the flexible polymer to bend and become more compact. This condensation process is monitored by circular dichroism spectroscopy and by electron microscopy of the DNA complexes. As shown in the electron photomicrographs in Fig. 1, complexes made using the anti-rat SC Fab-polylysine carrier are compact toroids approximately $25 \mathrm{~nm}$ in diameter. Small circular structures measuring $\sim 1 \mathrm{~nm}$ in diameter were noted in preparations of both the complexes and the conjugate alone, and most likely represents the anti-SC Fab-polylysine carrier. In comparison, a carrier consisting of galactosylated polylysine condensed individual DNA molecules into toroid structures measuring 10-12 $\mathrm{nm}$ in diameter (11).

In vivo transfection using the anti-secretory component Fab antibody-polylysine carrier. We tested the transfer of reporter genes into the airway epithelium in vivo by the systemic injection of a targeting complex consisting of the Fab portion of IgG directed against rat SC, the extracellular domain of pIgR, conjugated to poly-L-lysine, and noncovalently bound to reporter genes. The results of luciferase assays performed $6 \mathrm{~d}$ after infusion of the complexes in tissue homogenates extracted from liver, lungs, spleen, and heart are shown in Fig. 2. In animals injected with the anti-rat SC Fab-polylysine carrierDNA complex, we observed transgene expression in protein extracts from the liver and lungs, but not from the spleen and heart, tissues that do not express the pIgR (22). Furthermore, animals treated with the complexes prepared with an irrelevant plasmid (pCMV lacZ) bound to the bona fide carrier, or the expression plasmid (pGL2) bound to a carrier prepared with an irrelevant $\mathrm{Fab}$ fragment had no significant luciferase activity in any tissue examined. Tissues from animals injected with a mixture of the individual, nonconjugated components of the complex (not conjugated) also did not have transgene expression (data not shown). Thus, only tissues that contain cells bearing pIgR are transfected by our procedure, and DNA uptake 

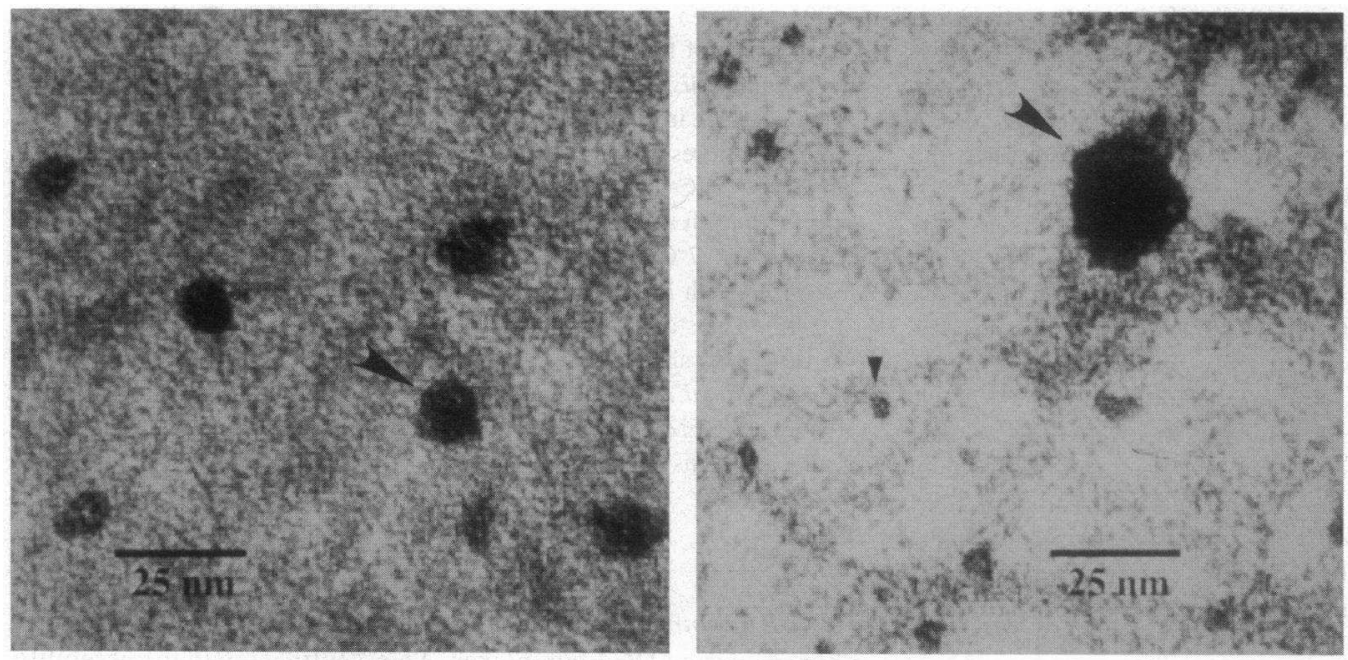

Figure 1. Electron micrograph of the anti-rat SC Fab-polylysine carrier-DNA complex. The anti-rat SC Fab-polylysine carrier-DNA complexes were formed as described in Methods, and a drop of the solution was immediately added to a 1,000-mesh electron microscope carbon grid, blotted, and stained with $0.04 \%$ uranyl acetate. The samples were diluted in water $(1: 40)$ before preparation for electron microscopy. The carrier-DNA complexes were examined using a JEOL-100C electron microscope, and are indicated in the photomicrograph by large arrowheads. For comparison, an electron micrograph of complexes made with the galactose-terminal glycoprotein carrier is shown. Complexes made using the anti-rat SC Fabpolylysine carrier appeared as toroid structures $\sim 25 \mathrm{~nm}$ in diameter; the smaller circular structures (small arrowhead) most likely represent the anti-SC Fab-polylysine carrier ( $\leq 1 \mathrm{~nm}$ in diameter). Bar, $25 \mathrm{~nm}$.

cannot be attributed to nonspecific introduction of an irrelevant Fab antibody-based complex.

The time course of luciferase expression is illustrated in Fig. 3. The maximum levels of luciferase activity was detected in the liver $4 \mathrm{~d}$ and lung $6 \mathrm{~d}$ after transfection, and achieved values of $13,795 \pm 4,431$ and $346,954 \pm 199,120$ integrated light units (ILU) per milligram of protein extract, respectively, that were statistically different than nontransfected controls. Again, spleen and heart did not have appreciable transgene expression (data not shown). Luciferase activity decreased to $\sim 1 \%$ of maximum values by day 12 (Fig. 3 ).

The transgene was detected in the lungs of animals $12 \mathrm{~d}$ after transfection by polymerase chain reaction amplification using primers specific for the luciferase gene (Fig. $4 a$ ). Amplification of DNA extracted from the lungs of nontransfected and mock-transfected rats did not demonstrate the transferred gene. Furthermore, the mRNA transcripts from the luciferase gene were detected in the lungs of rats after transfection by treating total cellular RNA with reverse transcriptase and amplifying the cDNA by the polymerase chain reaction, using oligonucleotide primers specific for the luciferase gene. All RNA samples were evaluated in the presence and absence of reverse transcriptase to further ensure that contamination with plasmid DNA had not occurred. As shown in Fig. $4 b$, luciferase transcripts were detected in the lungs of rats as long as $12 \mathrm{~d}$ after transfection, but not in nontransfected animals. No luciferase mRNA transcripts were noted in the absence of reverse transcriptase. As a control, mRNA from the endogenous GAPDH gene was identified in all of the corresponding samples (data not shown)

The tissue and cellular distribution of the transgene expression were examined in tissue sections from animals injected with other reporter genes. $3 \mathrm{~d}$ after the injection of complexes containing pCMV lacZ, tissue sections of trachea, lung, and liver underwent cytochemical staining for $\beta$-galactosidase activ- ity. An animal treated with complexes made using an irrelevant plasmid ( $\mathrm{pCMVIL2r)} \mathrm{served} \mathrm{as} \mathrm{a} \mathrm{control,} \mathrm{and} \mathrm{no} \mathrm{blue-stained}$ cells were detected in the tracheal epithelium or submucosal glands (Fig. $5 a$ ). As shown in Fig. $5 b$, expression of the transgene in the trachea was limited generally to the cells lining the epithelial surface. Six different tracheal sections and a total of 2464 cells were examined, and an average of $17.7 \%$ of the tracheal epithelial cells stained blue. Expression ranged from 10.9 to $27.7 \%$ of the airway epithelial cells in different sections. Although the staining appears to be localized to the apices of the tracheal epithelial cells at lower magnifications, higher magnification demonstrates blue staining throughout the cytoplasm conforming to the shape of the cell (Fig. $5 \mathrm{c}$ ). Both ciliated and secretory (goblet) respiratory epithelial cells expressed $\beta$-galactosidase, and blue-stained cells were also identified in the submucosal glands (Fig. $5 d$ ). However, transfection efficiency of the submucosal glands was difficult to determine accurately because few glands were found in sections of the proximal trachea. No expression from the transgene was detected in the terminal or respiratory bronchioles, or in the alveolar pneumocytes (data not shown).

The expression of $\beta$-galactosidase parallels the distribution of pIgR in the rat and human airway. As illustrated in Fig. 6, the $\mathrm{pIgR}$ was detected in the surface epithelium and submucosal glands of rat trachea, but not in alveoli. Confirmatory studies using the human IL2r, a surface protein that has been used as a reporter in the transduction of respiratory epithelial cells in vitro (23), as a reporter gene demonstrated that transgene expression was specifically localized in the airway epithelium. Immunofluorescence was specifically localized to the apical surface of numerous respiratory epithelial cells from the animal transfected with the plasmid pCMVIL2r (data not shown), which was absent from the airway epithelia of nontransfected rats or animals transfected with PCMV lacZ (data not shown). 


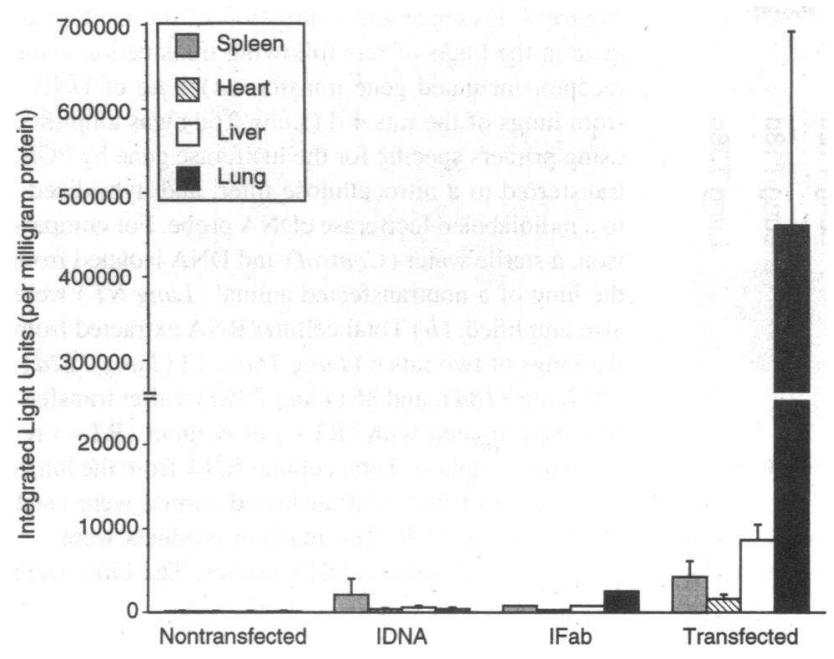

Figure 2. Tissue specificity and expression of pGEMluc introduced into rats using the anti-rat SC Fab-polylysine carrier. The plasmid pGL2 $(300 \mu \mathrm{g})$ complexed to the anti-rat SC Fab-based carrier was infused into the caudal vena cava of rats (Transfected, $n=4$ ). $6 \mathrm{~d}$ after injection the animals were killed and protein extracts from the spleen, heart, liver, and lung were assayed for luciferase activity. Animals treated with complexes consisting of the expression plasmid (pGL2) bound to a carrier made with irrelevant antibodies (IFab, $n=2)$ or an irrelevant plasmid (pCMV lacZ) bound to the authentic carrier (IDNA, $n=3$ ) were used as controls. Protein extracts from nontransfected rats (Nontransfected, $n=3$ ) were analyzed in parallel. Luciferase activity is expressed as integrated light units per milligram of total protein derived from cell lysates. Data are reported as mean \pm SEM, and evaluated by a nonparametric analysis of variance using the Kruskall-Wallis test. The level detected in the transfected lung was statistically different than nontransfected controls $(P<0.05)$.

Thus, expression in airways is observed whether the reporter gene is luciferase, $\beta$-galactosidase, or the human interleukin 2 receptor. In the liver, rare $(<1 \%)$, blue-stained hepatocytes were observed in animals transfected with pCMV lacZ, but not in either non-transfected or mock-transfected rats (data not shown).

\section{Discussion}

We report the successful transfer of reporter genes conjugated to anti-rat SC Fab-polylysine carrier into the airway epithelium in vivo. This technique specifically delivered the transgene to the liver and lung, tissues in which this receptor is expressed. Tissues that do not express the pIgR, spleen and heart, were not transfected. In addition, neither a conjugate prepared with irrelevant Fab fragments nor a complex prepared with a plasmid containing an irrelevant reporter gene produced detectable transgene activity. Thus, this complex specifically targets pIgRbearing tissues. The presence of the receptor's natural ligands, polymeric IgA and IgM, does not appear to prevent the uptake of the transgene in vivo. Transgene expression in tissues that contain receptor-bearing cells was maximal at $6 \mathrm{~d}$ after transfection, decreased to lower levels at $12 \mathrm{~d}$, and had virtually disappeared by eighteen days.

Several approaches permit the introduction of functional genes into cells of the respiratory tract in vivo, including replica-

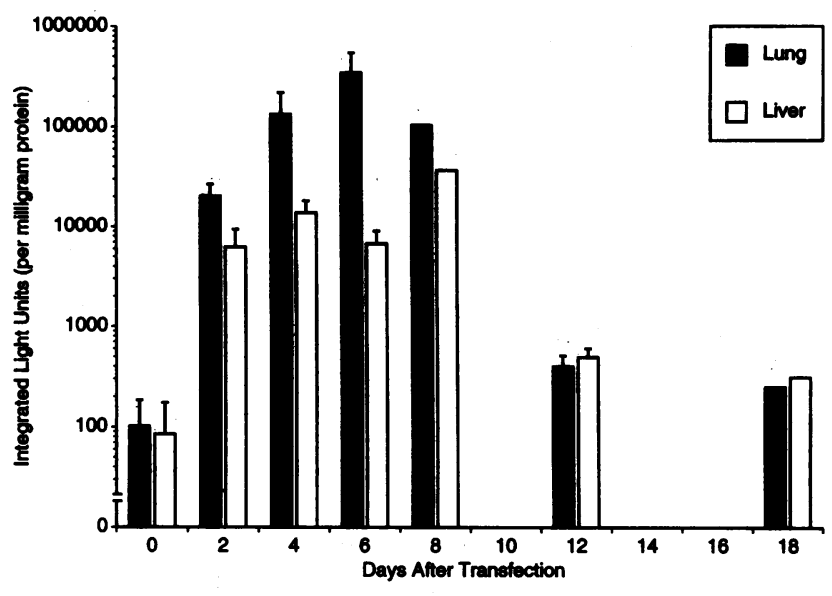

Figure 3. Duration of transgene expression after introduction into the livers and lungs of rats using the anti-rat SC Fab-polylysine carrier. In four separate experiments, $300 \mu \mathrm{g}$ of the plasmid pGL2 complexed to the anti-rat secretory component Fab antibody-carrier was infused into the caudal vena cava of rats. Animals were killed $2(n=3), 4(n=3)$, $6(n=4), 8(n=2), 12(n=3)$, and $18(n=2) \mathrm{d}$ after injection, and cell lysates from the liver and lung were assayed for luciferase expression. Protein extracts obtained from the livers and lungs of three untreated rats were used as controls. Data are reported as mean $\pm S E M$, and evaluated by a nonparametric analysis of variance using the Kruskall-Wallis test. Luciferase activity detected in the liver $4 \mathrm{~d}$ and the lung 4 and $6 \mathrm{~d}$ after transfection were statistically different than nontransfected controls $(P<0.05)$. (Open columns) Protein extracts from lung; (solid columns) protein extracts from liver.

tion deficient, recombinant adenoviruses (24-27), adeno-associated virus (28-30), and liposomes (31-35). Receptor-mediated gene transfer offers a large packaging capacity of genes and tissue specificity, and receptors other than pIgR have been used to target the airway. Reporter genes have been introduced into airway epithelia of intact animals using adenovirus-polylysine and human transferrin-adenovirus-polylysine carriers (12). In these experiments, disabled adenovirus served as both a ligand and an endosomolytic agent. Intratracheal instillation of DNA bound to these conjugates resulted in transient expression of the reporter gene which peaked $1 \mathrm{~d}$ after transfection and returned to pretreatment levels by $7 \mathrm{~d}$. However, we cannot directly compare the efficiency of the human transferrin-adenovirus-polylysine conjugates with the anti-SC Fab antibody-polylysine carrier. Differences in the route of administration, quantity of plasmid DNA delivered, and the specific cells and tissues targeted preclude such comparisons.

Receptor-mediated gene transfer via the pIgR has the benefit of being a noninfectious vector, specific for the targeted cells, that results in a significant level and duration of transgene expression. Specificity of delivery of corrective genes to affected cells may be important for gene therapy, since indiscriminate transgene expression may have detrimental effects. For example, the expression of the cystic fibrosis transmembrane conductance regulator in fibroblasts leads to dose-dependent growth inhibition (36). Moreover, this system permits the delivery of functional genes from the circulation. This ability of the antiSC Fab-based carrier to transfect only epithelial and submucosal gland cells in the airways may be an important advantage, since the approach from the blood may permit more uniform distribu- 


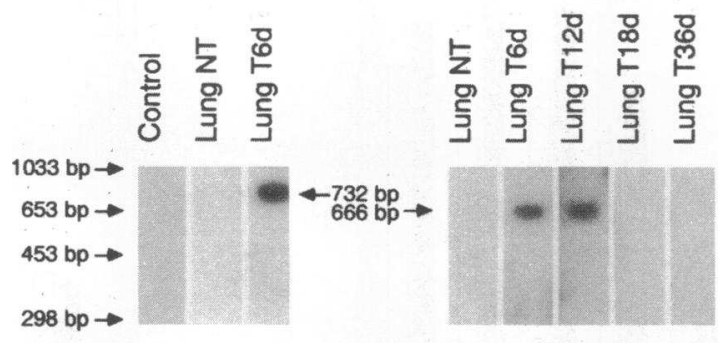

Reverse Transcriptase +

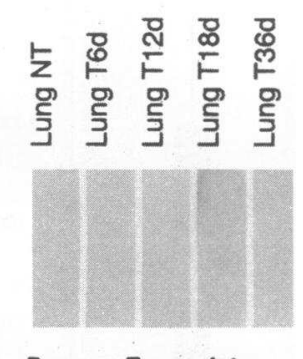

Reverse Transcriptase .

Figure 4. Presence and expression of the luciferase gene in the lungs of rats following transfection using receptor-mediated gene transfer. (a) $1 \mu \mathrm{g}$ of DNA from lungs of the rats $4 \mathrm{~d}$ (Lung T6d) was amplified using primers specific for the luciferase gene by PCR, transferred to a nitrocellulose filter, and hybridized to a radiolabeled luciferase cDNA probe. For comparison, a sterile water ( Control) and DNA isolated from the lung of a nontransfected animal (Lung NT) were also amplified. $(b)$ Total cellular RNA extracted from the lungs of two rats 6 (Lung T6d), 12 (Lung T12d), 18 (Lung T18d), and 36 (Lung T36d) d after transfection were treated with $(\mathrm{RT}+)$ or without $(\mathrm{RT}-)$ reverse transcriptase. Total cellular RNA from the lungs (Lung NT) of two nontransfected animal were used as controls. Using primers specific for the genes encoding luciferase, the resultant cDNA were amplified by PCR. The reaction products were separated by agarose gel electrophoresis, and analyzed by Southern blot hybridization using luciferase radiolabelled cDNA probes. The blots were exposed to radiographic film for $16 \mathrm{~h}$.

tion of the vector than delivery via the airway and could facilitate the approach to the submucosal glands.

Other important considerations for gene therapy are the extent and level of expression of the transgene. Studies in vitro suggest that correction of as few as $6 \%$ of cells in a cystic fibrosis epithelium with the cystic fibrosis transmembrane conductance regulator will produce electrophysiologic correction of the monolayer (23). By this criterion, targeting the pIgR may transfect a sufficient number of cells in the airway to be practical for treatment of cystic fibrosis. However, the determinants of the level of transgene expression in the different pIgRexpressing tissues are so far unclear from our studies. Maximal luciferase activity was an order of magnitude higher in tissue homogenates from the lung than in the liver, a difference all the more striking when one considers that most of the cells in the rodent liver, the hepatocytes, express the pIgR, whereas this receptor is expressed in few cells in the lung and respiratory tract (only epithelial cells in the large and medium sized airways). The data for luciferase expression are concordant with the expression of the lac $\mathrm{Z}$ transgene, which demonstrated rare hepatocytes positive for $\beta$-galactosidase activity while a significant number of airway epithelial cells showed a robust blue color after cytochemical staining. Because the data are consistent for two reporter genes (luciferase and lacZ) driven by two different promoters (SV40 and CMV regulatory elements), this difference may be less likely to be due to relative promoter strength or differences in protein processing in the two tissues. Nevertheless, marked variations have been observed in the expression of transgenes driven by viral promoter and enhancer elements in different tissues in transgenic animals $(37,38)$.

Several additional explanations for this difference in transgene expression are possible, including unequal levels of expression of the receptor, competition from the natural ligand, or the trafficking of the DNA-carrier complex in the particular cell. In rodents, pIgR expression, based on the production of $\mathrm{SC}$, is significantly greater in the liver than lung (39). Radiolabeled dIgA injected into the systemic circulation of rats is transported from blood to bile over 20 times more rapidly than it is transported into the airways (40). The efficient transcytosis which is prominent in hepatocytes may permit rapid transit of the complexes through hepatocytes, with little time to escape the endosome and be expressed. If transcytosis is less rapid in the airway, more of the carrier-DNA complex might escape from the transcytotic vesicles. The vascular distribution and clearance of anti-SC Fab antibodies may be different from the natural ligand. Finally, the relative efficiency of binding and trafficking of these antibodies in hepatocytes compared to respiratory epithelial cells has not been determined. Several of these possibilities can be tested experimentally.

No attempts were made to treat the airway epithelium to augment or prolong transgene expression in this study. Even so, in contrast to previous studies in which the airways were targeted by the transferrin receptor (12), transgene expression lasted for $>8 \mathrm{~d}$ without specific enhancement. This success may be attributable to the particular receptor being targeted or to the highly condensed form of the plasmid in the carrierDNA complex, which is smaller than others described in the literature (41). Since we have observed prolonged expression of transgenes in hepatocytes delivered using a galactosylated polylysine carrier (11), we believe that the compacted form of the plasmid contributes to the survival and the protracted expression of the transferred gene. This preparation of highly condensed DNA complexes using the anti-rat SC Fab-based carrier was different from that described in our previous work with the anti-human SC Fab-polylysine (2), and was patterned after the method of condensation we used for experiments to target the asialoglycoprotein receptor (11), though the exact concentrations of sodium chloride were different from those used with galactosylated polylysine carrier. Complexes made using the anti-SC Fab carrier-DNA complex were larger than those containing galactose-terminal glycoprotein (11), as judged by electron microscopy, most likely due to the effects of the Fab fragment on the interaction of the polycation and DNA, but are still substantially smaller than other reported complexes (41). The size of the complexes can be important because many endocytotic receptors discriminate against ligands of a determined size range in vivo $(42,43)$. We expect that the pIgR, however, can accommodate larger complexes than the asialoglycoprotein receptor. Indeed, the pIgR is adapted for the uptake of large, multimeric molecules, and immune complexes formed with its natural ligand can be efficiently internalized (44).

The size and structure of the complexes may also be important for its stability in the blood, receptor-ligand interaction, 

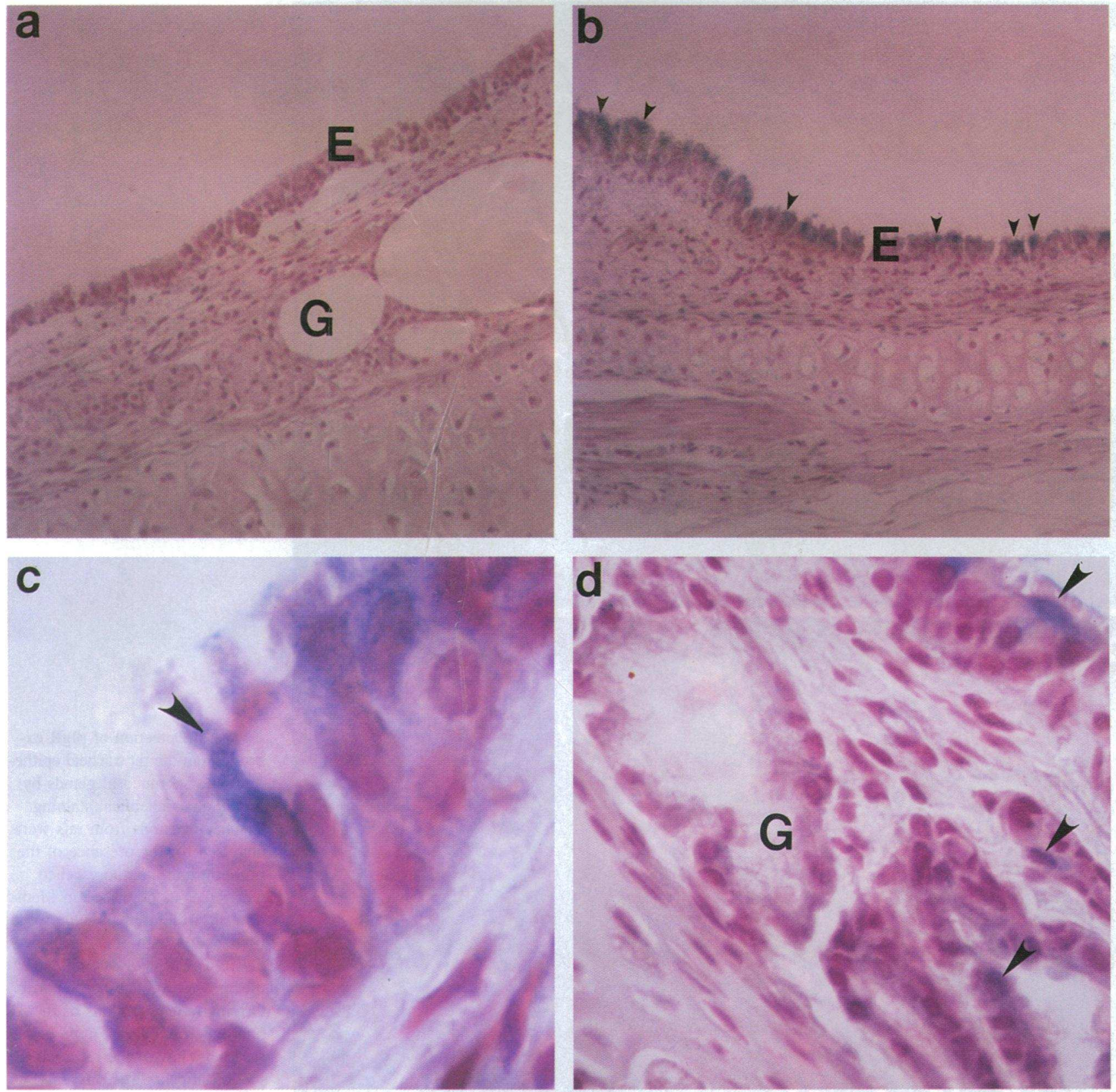

Figure 5. Photomicrographs of rat tracheal epithelial cells transfected with pCMVlacZ using the anti-rat secretory component Fab antibodypolylysine carrier. $300 \mu \mathrm{g}$ of the plasmid pCMV lacZ $(b-d)$ or PCMVIL2r $(a)$ complexed to the anti-rat SC Fab-based carrier was infused into the caudal vena cava of rats. After $3 \mathrm{~d}$, the tissue sections were fixed and stained with a solution containing $0.5 \% \mathrm{X}$-gal as described in Methods. Original magnifications of the photomicrographs are in parentheses. The airway epithelium $(E)$ and submucosal glands $(G)$ are shown, and bluestained cells are indicated by arrowheads. (a) Brightfield view of tracheal epithelial cells and submucosal glands from a rat after transfection with the plasmid pCMVIL2r and cytochemical staining with X-gal and counter-staining with nuclear fast red $(\times 100)$. $(b)$ Brightfield view of tracheal epithelial cells after transfection with the plasmid pCMV lacZ and cytochemical staining with X-gal $(\times 100)$. $(c)$ Higher magnification $(\times 400)$ of the epithelial cells of the trachea of a transfected rat. Distinct, blue staining is visible throughout the cytoplasm in the transfected epithelial cells. $(d)$ Higher magnification $(\times 400)$ of submucosal glands in sections from the proximal trachea of a transfected rat. Isolated, blue stained cells were observed in several of the epithelial cells and submucosal glands.

internalization, and resistance to endonuclease degradation (45). Moreover, the polylysine component of the carrier may assist in nuclear trafficking of the DNA, since the sequences responsible for the translocation of viral proteins into the nucleus are rich in lysine $(46,47)$. The degree of condensation of the DNA complex is dependent on several variables, including the concentration of sodium chloride, length of the polylysine, as well as the size, sequence, and state of the DNA (48, 49). Nevertheless, despite improvements in the production of the carrier-DNA complexes, considerable variability in the 

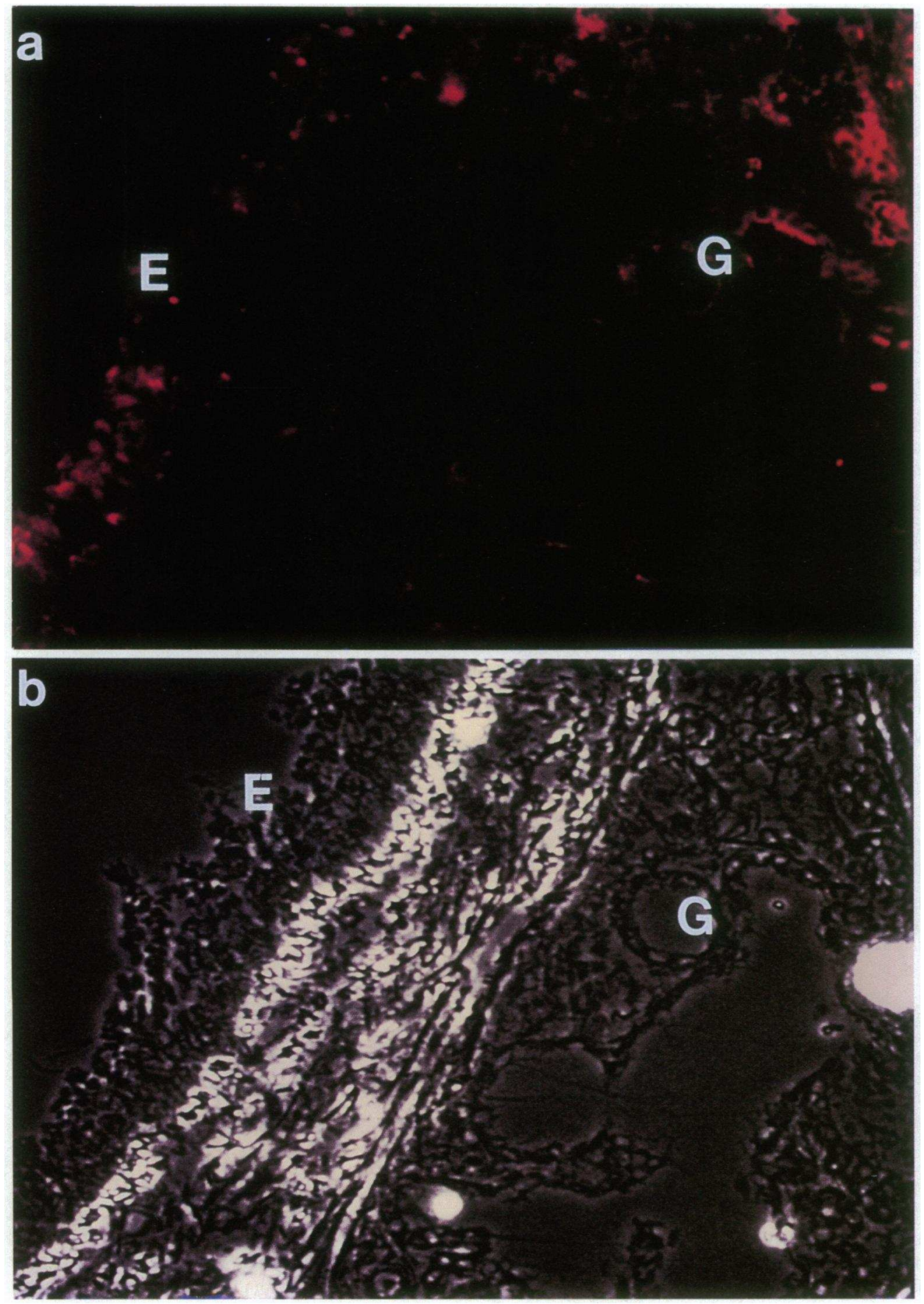

Figure 6. Detection of pIgR expression in the rat tracheal epithelium and submucosal glands by immunohistochemical staining. Tracheal sections from rats were analyzed for the presence of the pIgR by immunofluorescence techniques as described in Methods, after the animals underwent transfection with $300 \mu \mathrm{g}$ of the plasmid pCMV lacZ complexed to the anti-rat SC Fab-based carrier. Original magnifications of the photomicrographs are in parentheses. (a) View of the rat tracheal section after indirect immunofluorescence staining $(\times 200) .(b)$ phase contrast view of the same rat tracheal epithelium $(\times 200)$. The apical surface of the airway epithelium $(E)$ and submucosal glands $(G)$ are indicated.

level of transgene expression exists. Many of the sources of variability of this system remain uncertain.

Hepatocyte replication, stimulated by partial hepatectomy, greatly increases the level and persistence of transgene expression introduced by targeting the asialoglycoprotein receptor (8$10)$, apparently due to the prolonged survival of the transferred DNA in cytoplasmic endosomal vesicles (45). In our system of targeting epithelial cells, no pharmacologic or physiologic strategies were employed to disrupt the trafficking of the DNAcarrier complexes or increase the release of the foreign DNA from the endosomal compartments, which have been effective in increasing the expression of transgenes in vitro delivered via other receptors $(4,5)$. Therefore, the duration and level of expression reported here most likely represents the minimum that can be achieved with this method. Most of the DNA transferred into target cells by receptor-mediated endocytosis appears to exist as episomes $(7,9)$, and thus may not persist in the nuclei as the transfected cells divide. The DNA used in these experiments did not contain sequences designed to permit the transgene to persist in the target cell, either by integration or 
by episomal replication. If the transferred gene fails to persist in the target cell, repeated treatments will be required. Consequently, the immunologic properties of these DNA-carrier complexes will need to be investigated. Although the individual components of the complex are, by themselves, weak immunogens, the intact complex may be quite different.

In summary, the pIgR seems to be a promising receptor to target to achieve transgene delivery and expression in vivo. The distribution of this receptor in airway epithelium and the serous cells of the submucosal glands may be especially useful for the correction of the genetic defect that results in cystic fibrosis (13).

\section{Acknowledgments}

The authors wish to thank Aura Perez for her assistance with photomicrography, and Helga Beegen for her expert assistance with electron microscopy. We are indebted to Mitchell Drumm for providing us with the expression plasmid pCMVIL2r and Lloyd Culp for the pCMV lacZ plasmid. We would also like to thank Frank Mularo, Yoshie Hervey, Claudia Garner, and Cathy Silski for providing their expert technical support.

This study was supported by National Institutes of Health (NIH) grants DK-27651 and DK-43999, and a Research Development Program grant from the Cystic Fibrosis Foundation. C. S. Kaetzel was supported by NIH grants CA-51998 and AI-26449. R. W. Hanson was supported by NIH grants DK-21859 and DK-24451, and funds from the Pew Charitable Trusts and the Edison Program of the State of Ohio. J. C. Perales was supported by a Fulbright Fellowship awarded by the Ministry of Education and Science (Spain). E. Eckman was supported by the NIH Training grant T32 HL-07415. T. Ferkol was supported in part by the LeRoy Matthews Physician-Scientist Award from the Cystic Fibrosis Foundation and the Rainbow Babies and Childrens Hospital Board of Trustees New Investigator grant.

\section{References}

1. Cotton, M., E. Wagner, K. Zatloukal, S. Phillips, D. T. Curiel, and M. L. Birnstiel. 1992. High efficiency receptor-mediated delivery of small and large (48 kB) gene constructs using endosome disruption activity of defective or chemically-inactivated adenovirus particles. Proc. Natl. Acad. Sci. USA. 89:6094-6098.

2. Ferkol, T., C. S. Kaetzel, and P. B. Davis. 1993. Gene transfer into respiratory epithelial cells by targeting the polymeric immunoglobulin receptor. J. Clin. Invest. 92:2394-2400.

3. Cotten, M., F. Laengle-Rouault, H. Kirlappos, E. Wagner, K. Mechtler, M. Zenke, H. Beug, and M. L. Birnstiel. 1990. Transferrin-polycation mediated introduction of DNA into human leukemic cells: stimulation by agents that affect survival of transfected DNA or modulate transferrin receptor levels. Proc. Natl. Acad. Sci. USA. 87:4033-4037.

4. Wagner, E., C. Plank, K. Zatloukal, M. Cotten, and M. L. Birnstiel. 1992. Influenza virus hemagglutinin HA-2 N-terminal fusogenic peptides augment gene transfer by transferrin-polylysine-DNA complexes: toward a synthetic virus-like gene-transfer vehicle. Proc. Natl. Acad. Sci. USA. 89:7934-7938.

5. Curiel, D. T., S. Agarwal, E. Wagner, and M. Cotten. 1991. Adenovirus enhancement of transferrin-polylysine-mediated gene delivery. Proc. Natl. Acad. Sci. USA. 88:8850-8854.

6. Wu, G. Y., and C. H. Wu. 1988. Receptor-mediated gene delivery and expression in vivo. J. Biol. Chem. 263:14621-14624.

7. Wilson, J. M., M. Grossman, C. H. Wu, N. R. Chowdhury, G. Y. Wu, and J. R. Chowdhury. 1992. Hepatocyte-directed gene transfer in vivo leads to transient improvement of hypercholesterolemia in low-density lipoprotein receptordeficient rabbits. J. Biol. Chem. 267:963-967.

8. Wu, C. H., J. M. Wilson, and G. Y. Wu. 1989. Targeting genes: delivery and persistent expression of a foreign gene driven by mammalian regulator elements in vivo. J. Biol. Chem. 264:16985-16987.

9. Ferkol T., G. L. Lindberg, J. Chen, J. C. Perales, D. R. Crawford, O. D. Ratnoff, and R. W. Hanson. 1993. Regulation of the phosphoenolpyruvate carboxykinase/human factor IX gene introduced into the livers of adult rats by receptormediated gene transfer. FASEB (Fed. Am. Soc. Exp. Biol.) J. 7:1081-1091.

10. Wu, G. Y., J. M. Wilson, F. Shalaby, M. Grossman, D. A. Shafritz, and
C. H. Wu. 1991. Receptor-mediated gene delivery in vivo: partial correction of genetic analbuminemia in Nagase rats. J. Biol. Chem. 266:14338-14342.

11. Perales, J. C., T. Ferkol, H. Beegen, O. D. Ratnoff, and R. W. Hanson. 1994. Gene transfer in vivo: Sustained expression and regulation of genes introduced into the livers by receptor targeted uptake. Proc. Natl. Acad. Sci. USA. 91:4086-4090.

12. Gao, L., E. Wagner, M. Cotten, S. Agarwal, C. Harris, M. Romer, L. Miller, P.-C. Hu, and D. Curiel. 1993. Direct in vivo gene transfer to airway epithelium employing adenovirus-polylysine-DNA complexes. Hum. Gene Ther. 4:17-24.

13. Fiedler, M. A., C. S. Kaetzel, and P. B. Davis. 1991. Sustained production of secretory component by primary tracheal epithelial cells in primary culture. Am. J. Physiol. 261 (Lung Cell. Mol. Physiol.): L255-261.

14. Engelhardt, J. F., J. R. Yankaskas, S. A. Ernst, Y. Yang, C. R. Marino, R. C. Boucher, J. A. Cohn, and J. M. Wilson. 1992. Submucosal glands are the predominant site of CFTR expression in the human bronchus. Nature Genet. 2:240-247.

15. Chintalacharuvu, K. R., A. S. Tavill, L .N. Louis, J.-P. Vaerman, M. E. Lamm, and C. S. Kaetzel. 1994. Disulfide bond formation brtween dimeric immunoglobulin $A$ and the polymeric immunoglobulin receptor during hepatic transcytosis. Hepatology. 19:162-173.

16. Jung, G., W. Kohnlein, and G. Luders. 1981 Biological activity of the antitumor protein neocarzinostatin coupled to a monoclonal antibody by N-Succinimidyl 3-(2-pyridyldithio) proprionate. Biochem. Biophys. Res. Commun. 101:599-606.

17. Lin, W. C., and L. A. Culp. 1991. Selectable plasmid vectors with alternative and ultrasensitive histochemical marker genes. Biotechniques. 11:344-351.

18. Maniatis, T., E. F. Frisch, and J. Stambrook. 1989 Molecular Cloning: A Laboratory Manual. Cold Spring Harbor Laboratory Press, Cold Spring Harbor, New York.

19. Basbaum, C. B., and W. E. Finkbeiner. 1989. Mucus-producing cells of the airway. In Lung Biology in Health and Disease: Lung Cell Biology. D. Massaro, editor. Marcel Dekker, New York. 37-79.

20. Brasier, A. R., J. E. Tate, and J. F. Habener. 1989. Optimized use of the firefly luciferase assay as a reporter gene in mammalian cell lines. Biotechniques. 7:1116-1122.

21. Glantz, S. A. 1987. Biostatistics. McGraw-Hill Company, New York. 287-355.

22. Brandtzaeg, P., P. Krajci, M. E. Lamm, and C. S. Kaetzel. 1995. Epithelial and hepatobiliary transport of polymeric immunoglobulins. In Mucosal Immunology: Vol. I. Cellular Basis of Mucosal Immunity. P. L. Ogra, editor. Academic Press, Orlando, FL. In press.

23. Johnson, L. G., J. C. Olsen, B. Sarkadi, K. L. Moore, R. Swanstrom, and R. C. Boucher. 1992. Efficiency of gene transfer for restoration of normal airway epithelial function in cystic fibrosis. Nature Genet. 2:21-25

24. Rosenfeld, M. A., K. Yoshimura, B. C. Trapnell, K. Yoneyama, E. R. Rosenthal, W. Dalemans, M. Fukayama, J. Bargon, L. E. Stier, L. StratfordPerricaudet, M. Perricaudet, W. B. Guggino, A. Pavirani, J.-P. Lecocq, and R. G. Crystal. 1992. In vivo transfer of the human cystic fibrosis transmembrane conductance regulator gene to the airway epithelium. Cell. 68:143-155.

25. Rosenfeld, M. A., K. Yoshimura, L. E. Stier, B. C. Trapnell, L. StratfordPerricaudet, M. Perricaudet, W. Dalemans, S. Jallot, A. Mecemir, A. Pavirani, J.-P. Lecocq, and R. G. Crystal. 1991. Adenovirus-mediated transfer of a recombinant alpha-1-antitrypsin gene to the lung epithelium in vivo. Science (Wash. DC). 252:431-434.

26. Engelhardt, J. F., Y. Yang, L. D. Stratford-Perricaudet, E. D. Allen, K. Kozarsky, M. Perricaudet, J. R. Yankaskas, and J. M. Wilson. 1993. Direct gene transfer of human CFTR into human bronchial epithelia of xenografts with E1deleted adenoviruses. Nature Genet. 4:27-34.

27. Engelhardt, J. F., R. Simon, M. Zepeda, Y. Yang, and J. M. Wilson. 1993. Safety and efficacy of recombinant adenoviruses for lung directed gene therapy in nonhuman primates. Pediatr. Pulmonol. 9 (suppl.):184 (Abstr.).

28. Flotte, T. R., R. Solow, R. A. Owens, S. Afione, P. L. Zeitlin, and B. J. Carter. 1991. Gene expression from adeno-associated virus vectors in airway epithelial cells. Am. J. Respir. Cell Mol. Biol. 7:349-356.

29. Flotte, T. 1993. AAV vectors in the human airway: integration, immunity, and vector rescue. Pediatr. Pulmonol. 9 (suppl.):182-183 (Abstr.).

30. Flotte, T. R., S. Afione, R. Solow, M. L. Drumm, D, Markakis, W. B, Guggino, P. L. Zeitlin, and B. J. Carter. 1993. Expression of the cystic fibrosis transmembrane conductance regulator from a novel adeno-associated virus promoter. J. Biol. Chem. 268:3781-3790.

31. Hazinski, T. A., P. A. Ladd, and C. A. DeMatteo. 1991. Localization and induced expression of fusion genes in the rat lung. Am. J. Respir. Cell Mol. Biol. 4:206-209.

32. Yoshimura, K., M. A. Rosenfeld, H. Nakimura, E. M. Scherer, A. Pavirani, J.-P. Lecocq, and R. G. Crystal. 1992. Expression of the human cystic fibrosis transmembrane conductance regulator gene in a mouse lung after in vivo intratracheal plasmid-mediated gene transfer. Nucleic Acids Res. 20:3233-3240. 
33. Hyde, S., D. R. Gill, C. F. Higgins, A. E. O. Trezise, L. J. MacVinish, A. W. Cuthbert, R. Ratcliff, M. J. Evans, and W. H. Colledge. 1993. Correction of the ion transport defect in cystic fibrosis transgenic mice by gene therapy. Nature (Lond.). 362:250-255.

34. Alton, E. W. F. W., P. G. Middleton, N. J. Caplen, S. N. Smith, D. M. Steel, F. M. Munkonge, P. K. Jeffrey, D. M. Geddes, S. L. Hart, R. Williamson et al. 1993. Non-invasive liposome-mediated gene delivery can correct the ion transport defect in cystic fibrosis mutant mice. Nature Genet. 5:135-142.

35. Stribling, R., E. Brunnette, D. Liggett, K. Gaensler, and R. Debs. 1992. Aerosol gene delivery in vivo. Proc. Natl. Acad. Sci. USA. 89:11277-11281.

36. Stutts, M. J., S. E. Gabriel, J. C. Olsen, J. T. Gatzy, T. L. O'Connell, E. M. Price, and R. C. Boucher. 1993. Functional consequences of heterologous expression of the cystic fibrosis transmembrane conductance regulator in fibroblasts. J. Biol. Chem. 268:20653-20658.

37. Brinster, R. L., H. Y. Chen, A. Messing, T. van Dyke, A. J. Levine, and R. D. Palmiter. 1984. Transgenic mice harboring SV-40 T antigen genes develop characteristic brain tumors. Cell. 37:367-379.

38. Overbeek, P. A., S. Lai, K. R. Van Quil, and H. Westphal. 1986. Tissue specific expression in transgenic mice do a fused gene containing RSV terminal sequences. Science (Wash. DC). 231:1574-1577.

39. Sullivan, D. A., and C. R. Wira. 1983. Variations in free secretory component levels in mucosal secretions of the rat. J. Immunol. 130:1330-1335.

40. Huling, S., G. R. Fournier, A. Feren, A. Chuntharapai, and A. L. Jones. 1992. Ontogeny of the secretory immune system: Maturation of a functiona polymeric immunoglobulin receptor regulated by gene expression. Proc. Natl. Acad. Sci. USA. 89:4260-4264.

41. Wagner, E., M. Cotten, R. Foisner, and M. T. Birnstiel. 1991. Transferrin-
polycation-DNA complexes: the effect of polycations on the structure of the complex and DNA delivery to cells. Proc. Natl. Acad. Sci. USA. 88:4255-4259.

42. Bijsterbosch, M. K., G. J. Ziere, and T. J. C. Van Berkel. 1989. Lactosylated low density lipoprotein: A potential carrier for the site-specific delivery of drugs to Kupffer cells. Mol. Pharm. 36:484-486.

43. Bijsterbosch, M. K., and T. J. C. Van Berkel. 1990. Lactosylated low density lipoprotein: A potential carrier for the site-specific delivery of drugs to parenchymal liver cells. Biochem. J. 270:233-239.

44. Kaetzel, C. S., J. K. Robinson, K. R. Chintalacharuvu, J.-P. Vaerman, and M. E. Lamm. 1991. The polymeric immunoglobulin receptor (secretory component) mediates transport of immune complexes across epithelial cells: a local defense function for IgA. Proc. Natl. Acad. Sci. USA. 88:8796-8800.

45. Chowdhury, N. R., C. H. Wu, G. Y. Wu, P. C. Yerneni, V. R. Bommineni, and J. R. Chowdhury. 1993. Fate of DNA targeted to the liver by asialoglycoprotein receptor-mediated endocytosis in vivo. J. Biol. Chem. 268:11265-11271.

46. Kalderon, D., W. D. Richardson, A. F. Markham, and A. E. Smith. 1984 Sequence requirements for nuclear location of simian virus 40 large-T antigen. Nature (Lond.). 311:33-38

47. Bukrinsky, M. I., S. Haggerty, M. P. Dempsey, N. Sharova, A. Adzhubel, L. Spitz, P. Lewis, D. Goldfarb, M. Emerman, and M. Stevenson. 1993. A nuclear localization signal within HIV-1 matrix protein that governs infection of nondividing cells. Nature (Lond.). 365:666-669.

48. Timsit, Y., and D. Moras. 1991. Groove-backbone interaction in B-DNA implication for DNA condensation and recombination. J. Mol. Biol. 221:919940.

49. Eppler, K., E. Wyckoff, J. Goates, R. Parr, and S. Casjens. 1991. Nucleotide sequence of the bacteriophage P22 gene required for DNA packaging. Virology. 183:519-538. 